\title{
Correlation between Bax gene polymorphisms and esophagus cancer
}

\author{
LEI SUN, LINGYUN WEI, LEI WEI and DEMIN LI \\ Department of Cardio-Thoracic Surgery, The Affiliated Jinling Hospital of Nanjing \\ Medical University, Nanjing, Jiangsu 210002, P.R. China
}

Received November 29, 2017; Accepted September 3, 2018

DOI: $10.3892 / \mathrm{ol} .2018 .9511$

\begin{abstract}
The present study investigated the association between the G(-248)A single nucleotide polymorphism (SNP) in the promoter region of B-cell lymphoma 2 (Bcl-2) associated $\mathrm{X}$ protein (Bax), which is a pro-apoptosis gene and the clinicopathological parameters and prognosis of patients with esophagus cancer. Three genotypes (AA, AG and GG) of Bax G(-248)A SNP were detected in 75 patients with esophageal squamous cell carcinoma (ESCC) via polymerase chain reaction-restrictedfragmentlength polymorphism(PCR-RFLP). The expression of Bax in tumor tissues from 75 patients with ESCC and 30 para-carcinoma normal tissues were detected via immunohistochemistry. The association between the Bax protein expression and the Bax gene polymorphism was analyzed via the $\chi^{2}$ test. The clinical data of patients was collected and the association between Bax gene polymorphism and the pathological parameters and the prognosis of patients with ESCC was analyzed. The PCR-RFLP results revealed that the number of cases and the distribution frequencies of $\mathrm{GG}$, AG and AA genotypes of Bax polymorphism in patients with ESCC were 50 (66.67\%), 16 (21.33\%) and 9 (12\%), respectively. The immunohistochemical results revealed that the positive expression rate of Bax in ESSC tissues was $42.67 \%$. Bax protein expression was associated with the Bax gene polymorphism, which was associated with outer membrane infiltration, differentiation degree, lymphatic metastasis and the clinical staging of patients. The overall 5-year survival rate of patients was $38.6 \%(29 / 75)$. The survival analyses revealed that the prognosis of patients with AG+AA genotypes was favorable, while that of patients with GG genotype was poor. Bax gene polymorphism was associated with Bax gene expression, tumor staging and lymphatic metastasis in patients with ESCC, which is an influencing factor for the overall survival rate and may
\end{abstract}

Correspondence to: Dr Demin Li, Department of Cardio-Thoracic Surgery, The Affiliated Jinling Hospital of Nanjing Medical University, 305 Zhongshan Dong Road, Xuanwu, Nanjing, Jiangsu 210002, P.R. China

E-mail: drldm05@126.com

Key words: esophageal squamous cell carcinoma, B-cell lymphoma 2 associated $\mathrm{X}$ protein, gene polymorphism, prognosis be used as a reference index for the prognosis evaluation of patients with ESCC.

\section{Introduction}

Esophagus cancer is a common malignant tumor in the digestive tract, with incidence rate ranking fourth among all tumors (1). Although the incidence rate of Barrett's adenocarcinoma has increased rapidly in western countries, esophageal squamous cell carcinoma (ESCC) still holds a dominant position in East Asia and China (2). Currently there are many treatment methods, such as operation, chemotherapy and radiotherapy, but the 5-year survival rate of patients with esophagus cancer is still lower than $40 \%$, so new diagnosis and treatment methods still need to be further studied and explored (3).

B-cell lymphoma 2 (Bcl-2) associated X protein (Bax) is an important pro-apoptosis protein in Bcl-2 family, which has three structural domains: $\mathrm{BH} 1, \mathrm{BH} 2$ and $\mathrm{BH} 3$ (4). Under normal conditions, Bax proteins mainly exist in the cytoplasm. When cells receive various apoptosis signals, Bax proteins will transfer from the cytoplasm onto the mitochondrial membrane, and recognize $\mathrm{Bcl}-2$ proteins on the membrane through $\mathrm{BH} 3$ structural domain, binding to Bcl-2 to form the Bax-Bcl-2 heterodimer, thereby inhibiting the anti-apoptosis effect of Bcl-2 proteins (5). At the same time, Bax proteins can also form the Bax-Bax homodimer on the mitochondrial membrane, thus increasing the permeability of mitochondrial membrane and releasing cytochrome $\mathrm{C}$ into the cytoplasm to activate the cascade apoptosis response. Therefore, Bax is an important regulator of the mitochondrial apoptosis signaling pathway $(6,7)$.

Currently, there are few reports on the correlation between Bax gene polymorphism and tumors, but the G(-248)A site of Bax gene promoter has been studied (8). Studies have found that the polymorphism of G(-248)A site can down-regulate the activity of Bax promoter, and affect the Bax gene transcription and protein expression, ultimately increasing the $\mathrm{Bcl}-2 / \mathrm{Bax}$ ratio, and inhibiting the apoptosis process of tumor cells (9-11).

In order to investigate the correlation between Bax gene polymorphism, clinicopathological features and survival prognoses of ESCC patients, this study utilized polymerase chain reaction-restricted fragment length polymorphism (PCR-RFLP) to detect the Bax gene polymorphism of genomic DNA in peripheral blood in ESCC patients, and adopted immunohistochemistry to detect the Bax expression in ESCC tissues, and 
analysed the correlation between Bax gene polymorphism and Bax protein expression, and then clinicopathological parameters and survival prognosis of ESCC patients were studied.

\section{Patients and methods}

Materials. The paraffin-embedded specimens of tumor tissues of 75 ESCC patients were collected. A total of 37 males and 38 females aged 24-78 years were included in this study, with a median age of 52 years. All the patients received operation in the Affiliated Jinling Hospital of Nanjing Medical University (Nanjing, China) from June 2009 to March 2012. The patients were pathologically diagnosed with ESCC and underwent operative treatment for the first time without receiving chemotherapy, radiotherapy and other treatments. This study was reviewed and approved by the Ethics Committee of the Affiliated Jinling Hospital of Nanjing Medical University, and all patients or their families signed the informed consent.

Tools included in this study: DNA extraction kits and reverse transcription-polymerase chain reaction (RT-PCR) kits (Invitrogen; Thermo Fisher Scientific, Inc., Waltham, MA, USA); restriction endonuclease Aci I (New England Biolabs, Wilbury WayHitchin, Herts, UK); rabbit monoclonal Bax antibody (1:100; cat. no. ab32503, Abcam; Cambridge, MA, USA); immunohistochemical staining kits SP-9001 (Zhongshan Goldenbridge Biotechnology, Beijing, China); primer synthesis (Takara, Dalian, China).

Detection of Bax genotypes of ESCC patients via PCR-RFLP. At admission, $5 \mathrm{ml}$ fasting venous blood was collected from all patients and stored in a refrigerator at $4^{\circ} \mathrm{C}$ after heparin anticoagulation. Then the chromosomal DNA in peripheral blood karyocytes was extracted according to the instructions of DNA extraction kit, followed by PCR amplification reaction. The forward and reverse primers of enzyme digestion PCR: 5'-CGGGGTTATCTCTTGGGC-3' and 5'-GTGAGA GCCCCGCTGAAC-3'. The specific reaction conditions are as follows: $95^{\circ} \mathrm{C}$ for $5 \mathrm{~min}, 95^{\circ} \mathrm{C}$ for $30 \mathrm{sec}, 55^{\circ} \mathrm{C}$ for $30 \mathrm{sec}$, $72^{\circ} \mathrm{C}$ for $1 \mathrm{~min}$, in total 40 cycles; extension at $72^{\circ} \mathrm{C}$ for $5 \mathrm{~min}$. Finally, the enzyme digestion of PCR products was performed via the restriction endonuclease Aci I.

Detection of Bax protein expression in tissues of ESCC patients via immunohistochemistry. The Bax protein expression in tissues of ESCC patients was detected via streptomycin avidin-peroxidase (SP) method. The tissue section was dewaxed routinely by xylene and hydrated by gradient ethanol; then $3 \% \mathrm{H}_{2} \mathrm{O}_{2}$ solution was used to eliminate the activity of endogenous peroxidase, followed by high pressure boiling and antigen retrieval. The primary rabbit monoclonal Bax antibody was added dropwise and the mixture was placed in the refrigerator at $4^{\circ} \mathrm{C}$ overnight. Then, the mixture was washed with phosphate buffered saline (PBS) $(0.01 \mathrm{M})$ and added with secondary goat anti-rabbit (HRP) IgG antibody (1:2,000; cat. no. ab6721; Abcam) for incubation at $37^{\circ} \mathrm{C}$ for $1 \mathrm{~h}$, followed by another wash with PBS, color development via diaminobenzidine (DAB), re-staining via hematoxylin, and photographing under the TE2000-U microscope (Nikon, Tokyo, Japan).

The staining results were evaluated by the two-level scoring method. First, based on the staining intensity:
Table I. Correlation between Bax gene polymorphisms and protein expression in esophageal squamous cell carcinoma tissues.

\begin{tabular}{lccccc}
\hline \multicolumn{4}{c}{$\begin{array}{c}\text { Bax G(-248)A single } \\
\text { nucleotide polymorphism }\end{array}$} & & \\
\cline { 2 - 3 } Bax & AG/AA genotype & GG genotype & & r & P-value \\
\hline Positive & 4 & 28 & 0.793 & $<0.01$ \\
Negative & 21 & 22 & & \\
\hline
\end{tabular}

Bax, B-cell lymphoma-2 associated $\mathrm{X}$ protein.

No color, 0 point; pale yellow, 1 point; brown yellow, 2 points; dark brown, 3 points. Then, based on the percentage of positive cells: Percentage of positive cells $<5 \%, 0$ point; $5-25 \%, 1$ point; $26-50 \%, 2$ points; $>50 \%, 3$ points. The two scores were added up: $>3$ points, positive expression; $\leq 2$ points, negative expression. Finally, the results were statistically analyzed.

Correlation of Bax genotypes with pathological parameters of ESCC tissues. In this study, the number of cases with AA genotype was small, so AG and AA genotypes were combined into AG+AA group. A total of 75 ESCC patients were divided into GG group and AG+AA group. According to clinical data of patients, the correlation between Bax genotypes and pathological parameters of patients was analyzed via $\chi^{2}$ test.

Correlation of Bax genotypes with survival prognosis of ESCC patients. All of 75 patients were followed up after operation for 5 years and the follow-up rate was $100 \%$. The survival time was from the 1st day after operation to the death of patients or the last date of follow-up; the statistical analyses were performed each month.

Statistics processing. SPSS software (version 17.0, SPPSS Inc., Chicago, IL, USA) was used for the data processing in this study. Data were presented as mean $\pm \mathrm{SD}$. $\chi^{2}$ test was used for the intergroup comparison of enumeration data; Spearman's test was used for the correlation analysis; Kaplan-Meier method was used for the univariate survival analysis and Log-rank method was used to detect the differences of survival curve. $P \leq 0.05$ was considered to indicate a statistically significant difference.

\section{Results}

Detection of Bax gene polymorphism in ESCC patients via PCR-RFLP. PCR-RFLP results showed that the GG genotype appeared in 256 and 96 bp fragments, AG genotype appeared in 352 and 256 bp fragments, and AA genotype appeared in $352 \mathrm{bp}$ fragment. According to the data statistics of all patients, the number of cases and distribution frequencies of $\mathrm{GG}, \mathrm{AG}$ and AA genotypes were 50 (66.67\%), 16 (21.33\%) and $9(12 \%)$, respectively (Fig. 1).

Detection of Bax protein expression in pathological tissues via immunohistochemistry. The immunohistochemical detection results revealed that the positive immunohistochemical 


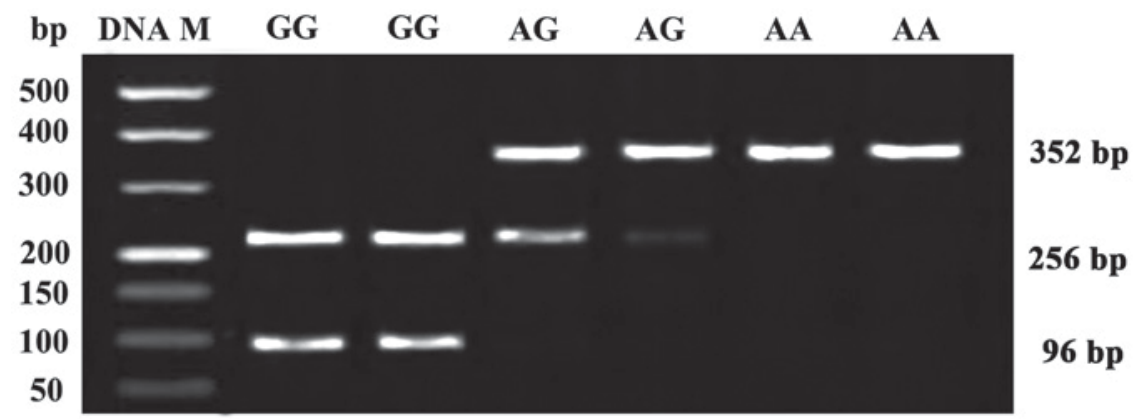

Figure 1. Detection of Bax gene polymorphism in patients with esophageal squamous cell carcinoma via polymerase chain reaction-restricted fragment length polymorphism.

A

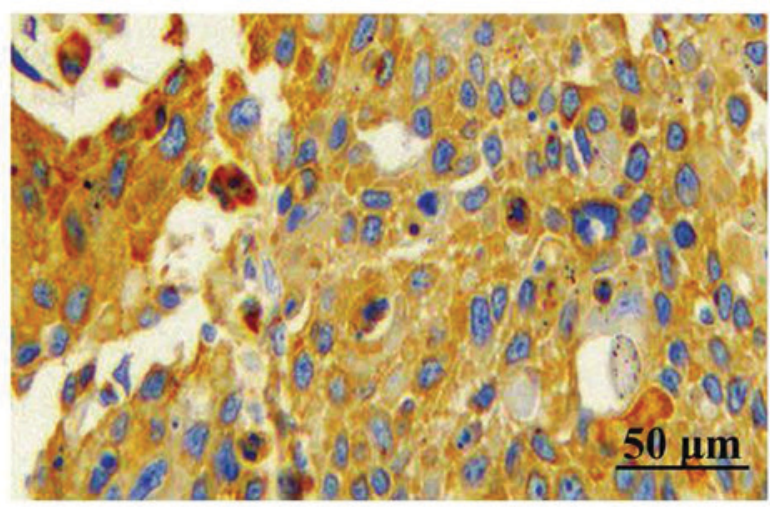

B

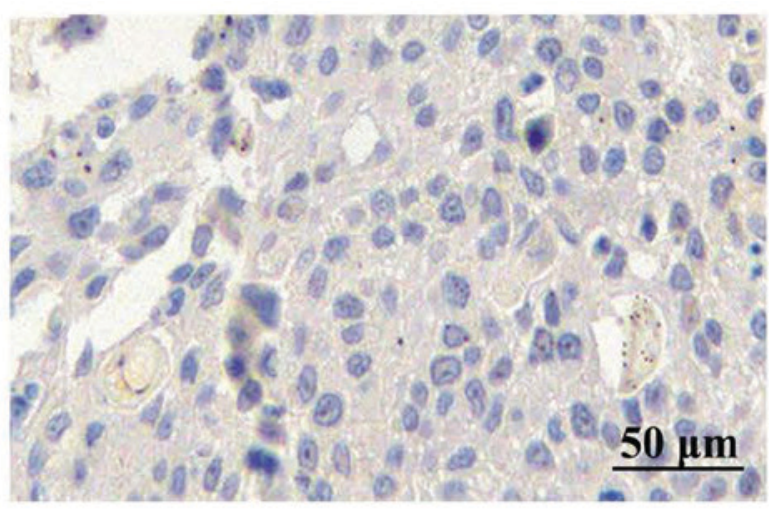

Figure 2. Detection of Bax protein expression in esophageal squamous cell carcinoma tissues via immunohistochemistry (magnification, x200; scale bars, $50 \mu \mathrm{m}$ ). (A) positive and (B) negative. Bax, B-cell lymphoma-2 associated X protein.

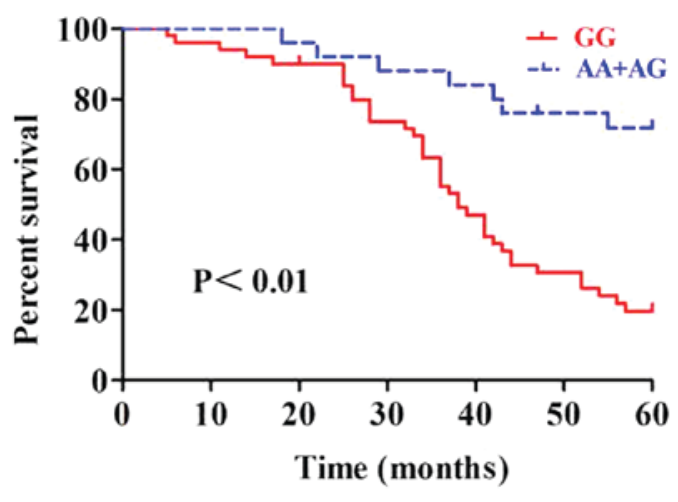

Figure 3. Bax expression and Kaplan-Meier survival curve of patients with esophageal squamous cell carcinoma. Bax, B-cell lymphoma-2 associated $\mathrm{X}$ protein.

staining of Bax showed brown yellow or dark brown, and Bax proteins mainly existed in the cytoplasm. According to the statistical results of staining scores, the positive expression rate of Bax in ESCC tissues was $42.67 \%$ (32/75) (Fig. 2).

Relationship between Bax gene polymorphism and Bax protein expression. Among 75 ESCC patients, there were 4 cases with positive Bax and AG/AA genotypes, 28 cases with positive Bax and GG genotype, 21 cases with negative Bax and AG/AA genotypes and 22 cases with negative Bax and GG genotype. Spearman's analysis was used to analyze the relationship between Bax gene polymorphism and Bax protein expression, and the results showed that the Bax gene polymorphism was positively correlated with the Bax protein expression ( $\mathrm{r}=0.793 ; \mathrm{P}<0.01$; Table I).

Correlation of Bax gene polymorphism with clinicopathological indexes of ESSC. The analysis results of the correlations between Bax gene polymorphism and clinicopathological indexes of ESSC are shown in Table II. $\chi^{2}$ test revealed that the Bax gene polymorphism was associated with the outer membrane infiltration, differentiation degree, lymphatic metastasis and clinical staging of patients $(\mathrm{P}<0.01)$, but not related to the sex and age $(\mathrm{P}>0.05)$.

Relationship between Bax gene polymorphism and survival prognosis of patients. A total of 75 ESCC patients were followed up; there were 29 survivors and 46 deaths during 5 years. Kaplan-Meier survival curve of 75 patients with Bax gene polymorphism was analyzed, and the results showed that the prognosis of patients with AG+AA genotypes was favorable, while that of patients with GG genotype was poor (Fig. 3). The differences in total survival curve were analyzed via Log-rank test, and the effect of Bax gene polymorphism on the overall survival rate of ESCC patients was statistically significant $(\mathrm{P}<0.01)$.

\section{Discussion}

Esophagus cancer is a malignant tumor with a high incidence rate, and its incidence and death rate tops the list in malignant 
Table II. Correlation between Bax gene polymorphism and clinicopathological indexes of ESSC (n, \%).

\begin{tabular}{|c|c|c|c|c|c|}
\hline Pathological parameter & Case & AG/AA genotype (\%) & GG genotype (\%) & $\chi^{2}$ & P-value \\
\hline Sex & & & & 0.11 & $>0.05$ \\
\hline Male & 37 & $13(35.14)$ & $24(64.86)$ & & \\
\hline Female & 38 & $12(31.58)$ & $26(68.42)$ & & \\
\hline Age (years) & & & & 0.43 & $>0.05$ \\
\hline$\geq 50$ & 41 & $15(36.59)$ & $26(63.41)$ & & \\
\hline$<50$ & 34 & $10(29.41)$ & $24(70.59)$ & & \\
\hline Outer membrane infiltration & & & & 17.03 & $<0.01$ \\
\hline Yes & 43 & $6(13.95)$ & $37(86.05)$ & & \\
\hline No & 32 & $19(59.38)$ & $13(40.63)$ & & \\
\hline Differentiation degree & & & & 19.47 & $<0.01$ \\
\hline High & 39 & $4(10.26)$ & $35(89.74)$ & & \\
\hline Low & 36 & $21(58.33)$ & $15(41.67)$ & & \\
\hline Lymphatic metastasis & & & & 7.74 & $<0.01$ \\
\hline Yes & 35 & $6(17.14)$ & $29(82.86)$ & & \\
\hline No & 40 & $19(47.50)$ & $21(52.50)$ & & \\
\hline Clinical staging & & & & 8.24 & $<0.01$ \\
\hline I-II & 28 & $15(53.57)$ & $13(46.43)$ & & \\
\hline III-IV & 47 & $10(21.28)$ & $37(78.72)$ & & \\
\hline
\end{tabular}

Bax, B-cell lymphoma-2 associated X protein.

tumors (1). The incidence rate of esophagus cancer in developing countries is higher than that in developed countries, and the new-onset patients in developing countries every year account for $\sim 80 \%$ of the total in the world (12). In China, esophagus cancer has a relatively high incidence rate, ranking fifth in malignant tumors, and its death rate ranks fourth in malignant tumors. In some high-risk areas, esophagus cancer even becomes the most common malignant tumor, seriously affecting people's life and health (13). Pathogenesis and mechanisms of occurrence and development of esophagus cancer are very complicated; currently, studies have shown that the causes of esophagus cancer mainly include environmental factors, dietary habit, smoking, drinking and genetic factors $(14,15)$.

Studies have found that the Bax expression in esophagus cancer tissues is significantly lower than that in normal esophageal epithelial tissues and the Bax expression is negatively correlated with the tumor differentiation degree of patients (16). It was found in the study on colon cancer that the Bax protein is a key indicator of prognosis of benign colorectal cancer $(17,18)$. Recent study has shown that L3, a novel target gene, is closely related to the proliferation of tumor cells and has an important correlation with the ratio of bcl-2/bax in colon cancer tissues (19). Katkoori et al found that the tumor staging and metastasis of patients with positive Bax expression are superior to those of patients with negative Bax expression; besides, the survival analyses showed that the Bax protein is an influencing factor of survival of patients (20).

Single nucleotide polymorphism (SNP) is one of the important factors of differences in hereditary characters of different individuals, which is the most basic molecular foundation of genetic polymorphism, leading to differences in the susceptibilities of individuals to diseases and drugs (21). At present, there are many studies on Bax G(-248)A polymorphism in leukemia. Previous evidence showed that AG/AA genotypes reduce chemotherapy resistance and prolong the survival time of patients with chronic lymphocytic leukemia (22). Many studies have shown that the Bax protein is lowly expressed in tissues of patients with AG/AA genotypes, mainly because the A allele can inhibit the Bax protein expression $(23,24)$. In the study on breast cancer, it was found that the Bax protein expression is negatively correlated with the differentiation degree, lymphatic metastasis and distal metastasis of breast cancer, and the clinicopathological indexes of patients with negative Bax expression are poorer than those of patients with positive Bax expression (25).

To further investigate the effect of Bax gene polymorphism on Bax protein expression in tumor tissues of ESCC patients, as well as its effects on pathological parameters and survival prognoses of ESCC patients, this study detected three genotypes (AA, AG and GG) of Bax G(-248)A SNP in 75 ESCC patients via PCR-RFLP, and found that the number of cases and distribution frequencies of GG, AG and AA genotypes of Bax polymorphism in ESCC patients were 50 (66.67\%), 16 (21.33\%) and 9 (12\%), respectively. The immunohistochemical results revealed that the positive expression rate of Bax in ESSC tissues was $42.67 \%$. Moreover, $\chi^{2}$ test revealed that the Bax protein expression was associated with the Bax gene polymorphism. Furthermore, combined with clinicopathological parameters of patients, it was found that the Bax gene polymorphism was related to the outer membrane infiltration, differentiation degree, lymphatic metastasis and clinical staging of patients. The overall 5-year survival rate of patients was 38.6\% (29/75). 
Univariate Kaplan-Meier survival analyses were performed to analyze effects of Bax gene polymorphism on overall survival curve of patients; the results showed that the prognosis of patients with $\mathrm{AG}+\mathrm{AA}$ genotypes was favorable, while that of patients with $\mathrm{GG}$ genotype was poor.

In conclusion, Bax gene polymorphism is related to the Bax gene expression, tumor staging and lymphatic metastasis of ESCC patients, which is an influencing factor of overall survival rate of ESCC patients, and can be used as a reference index for prognosis evaluation of ESCC patients.

\section{Acknowledgements}

Not applicable.

\section{Funding}

No funding was received.

\section{Availability of data and materials}

The datasets used and/or analyzed during the present study are available from the corresponding author on reasonable request.

\section{Authors' contributions}

LS drafted the manuscript. LS and LiW collected and interpreted the data. LS and LeW performed the PCR. DL performed the immunohistochemical analysis. All authors read and approved the final manuscript.

\section{Ethics approval and consent to participate}

The present study was approved by the Ethics Committee of the Affiliated Jinling Hospital of Nanjing Medical University (Nanjing, China). Written informed consent was obtained from all patients.

\section{Patient consent for publication}

Not applicable.

\section{Competing interests}

The authors declare that they have no competing interests.

\section{References}

1. Jemal A, Bray F, Center MM, Ferlay J, Ward E and Forman D: Global cancer statistics. CA Cancer J Clin 61: 69-90, 2011.

2. Mathé EA, Nguyen GH, Bowman ED, Zhao Y, Budhu A, Schetter AJ, Braun R, Reimers M, Kumamoto K, Hughes D, et al: MicroRNA expression in squamous cell carcinoma and adenocarcinoma of the esophagus: Associations with survival. Clin Cancer Res 15: 6192-6200, 2009.

3. Tepper J, Krasna MJ, Niedzwiecki D, Hollis D, Reed CE, Goldberg R, Kiel K, Willett C, Sugarbaker D and Mayer R: Phase III trial of trimodality therapy with cisplatin, fluorouracil, radio-therapy, and surgery compared with surgery alone for esophageal cancer: CALGB 9781. J Clin Oncol 26: 1086-1092, 2008.

4. Yi S and Tsao MS: Activation of hepatocyte growth factor-met autocrine loop enhances tumorigenicity in a human lung adenocarcinoma cell line. Neoplasia 2: 226-234, 2000.
5. Carneiro F and Sobrinho-Simoes M: The prognostic significance of amplification and overexpression of c-met and c-erb B-2 in human gastric carcinomas. Cancer 88: 238-240, 2000.

6. Brady HJ and Gil-Gómez G: Bax. The pro-apoptotic Bcl-2 family member, Bax. Inter J Biochem Cell Biol 30: 647-650, 1998.

7. Lu QL, Abel P, Foster CS and Lalani EN: bcl-2: Role in epithelial differentiation and oncogenesis. Hum Pathol 27: 102-110, 1996.

8. Chen K, Hu Z, Wang LE, Sturgis EM, El-Naggar AK, Zhang W and Wei Q: Single-nucleotide polymorphisms at the TP53-binding or responsive promoter regions of BAX and BCL2 genes and risk of squamous cell carcinoma of the head and neck. Carcinogenesis 28: 2008-2012, 2007.

9. Young RL and Korsmeyer SJ: A negative regulatory element in the bcl-2 5'-untranslated region inhibits expression from an upstream promoter. Mol Cell Biol 13: 3686-3697, 1993.

10. Kaderi MA, Norberg M, Murray F, Merup M, Sundström C, Roos G, Aleskog A, Karlsson K, Axelsson T, Tobin G and Rosenquist R: The BCL-2 promoter (-938C $>$ A) polymorphism does not predict clinical outcome in chronic lymphocytic leukemia. Leukemia 22: 339-343, 2008.

11. Kidd LR, Coulibaly A, Templeton TM, Chen W, Long LO, Mason T, Bonilla C, Akereyeni F, Freeman V, Isaacs W, et al: Germline BCL-2 sequence variants and inherited predisposition to prostate cancer. Prostate Cancer Prostatic Dis 9: 284-292, 2006.

12. Parkin DM, Bray FI and Devesa SS: Corrigendum to 'Cancer burden in the year 2000. The global picture'. Eur J Cancer 37 (Suppl 8): S4-S66, 2001.

13. Zhang SW, Zhang M and Li GL: An analysis of incidence and mortality of esophageal cancer in China, 2003-2007. China Cancer 4: 241-247, 2012.

14. Lin Y, Totsuka Y, He Y, Kikuchi S, Qiao Y, Ueda J, Wei W, Inoue $\mathrm{M}$ and Tanaka $\mathrm{H}$ : Epidemiology of esophageal cancer in Japan and China. J Epidemiol 23: 233-242, 2013.

15. Zhang T and Hou P: Research progress on etiology of esophageal cancer. Sichuan J Anat 3: 28-30, 2015.

16. Sarbia M, Bittinger F, Grabellus F, Verreet P, Dutkowski P, Willers R and Gabbert HE: Expression of Bax, a pro-apoptotic member of the Bc-1 2 family, in esophageal squamous cell carcinoma. Int J Cancer 73: 508-513, 1997.

17. Ogura E, Senzaki H, Yamamoto D, Yoshida R, Takada H, Hioki K and Tsubura A: Prognostic significance of Bcl-2, Bcl-xL/S, Bax and Bak expressions in colorectal carcinomas. Oncol Rep 6: 365-369, 1999.

18. Schelwies K, Sturm I, Grabowski P, Scherübl H, Schindler I, Hermann S, Stein H, Buhr HJ, Riecken EO, Zeitz M, et al: Analysis of p53/BAX in primary colorectal carcinoma: Low BAX protein expression is a negative prognostic factor in UICC stage III tumors. Int J Cancer 99: 589-596, 2002.

19. Russo A, Maiolino S, Pagliara V, Ungaro F, Tatangelo F, Leone A, Scalia G, Budillon A, Quaglia F and Russo G: Enhancement of 5-FU sensitivity by the proapoptotic rpL3 gene in p53 null colon cancer cells through combined polymer nanoparticles. Oncotarget 7: 79670-79687, 2016.

20. Katkoori VR, Suarez-Cuervo C, Shanmugam C, Jhala NC, Callens T, Messiaen L, Posey J III, Bumpers HL, Meleth S, Grizzle WE and Manne U: Bax expression is a candidate prognostic and predictive marker of colorectal cancer. J Gastrointest Oncol 1: 76-89, 2010.

21. Wang DG, Fan JB, Siao CJ, Berno A, Young P, Sapolsky R, Ghandour G, Perkins N, WinchesterE, Spencer J, et al: Large-scale identification, mapping and genotyping of single-nucleotide polymorphisms in the human genome. Science 280: 1077-1082, 1998.

22. He M, Chen MH, Xie HZ, Yao SZ, Zhu B, Feng LP and Wu YP: Transvaginal removal of ectopic pregnancy tissue and repair of uterine defect for caesarean scar pregnancy. BJOG 118: 1676-1677, 2011.

23. Li N, Zhu F, Fu S and Shi X: Transvaginal ultrasound-guided embryo aspiration plus local administration of low-dose methotrexate for caesarean scar pregnancy. Ultrasound Med Biol 38: 209-213, 2012.

24. Coniglio C and Dickinson JE: Pregnancy following prior Caesarean scar pregnancy rupture: Lessons for modern obstetric practice. Aust N Z J Obstet Gynaecol 44: 162-165, 2004.

25. Yao Q, Chen J, Lv Y, Wang T, Zhang J, Fan J and Wang L: The significance of expression of autophagy-related gene Beclin, Bcl-2, and Bax in breast cancer tissues. Tumour Biol 32: 1163-1171, 2011.

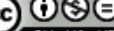

This work is licensed under a Creative Commons Attribution-NonCommercial-NoDerivatives 4.0 International (CC BY-NC-ND 4.0) License. 